CENDEKIA, Vol. 13. No. 1 April 2019

p-ISSN: 1978-2098; e-ISSN: 2407-8557

Https://soloclcs.org; Email: cendekiaoslo@gmail.com

Center of Language and Cultural Studies, Surakarta, Indonesia

Basrowi. 2019. Pemenfaatan Media Sosial oleh Tenega Kerja Indonesia dalam Proses

Pendidikan Anak Menggunakan Metode Belajar Long Distance Relationship.

Cendekia (2019), 13(1): 1-18. Https//doi.org/10.30957/cendekia.v13i1.59.

\title{
Pemanfaatan Media Sosial oleh Tenaga Kerja Indonesia dalam Proses Pendidikan Anak Menggunakan Metode Belajar Long Distance Relationship
}

\section{Basrowi}

\section{Sekolah Tinggi Ekonomi dan Bisnis Islam Lampung, Indonesia Email: basrowi2018@gmail.com}

\begin{abstract}
At present, social media is more widely used by migrant workers and TKI children just for the daily communication. The function of the social media is done in trivialities because both parties operationally can maximazie the media more specifically especially to improve the process of education and learning between parents to their children. This study draws problem of how social media can be used by TKI in educating children, through the LDR (Long Distance Relationship) method. This study used qualitative descriptive approach to analyze the data. The research subjects who acted as respondents were migrant workers and former migrant workers from Lampung Province. The results show that learning models using the LDR Method could be applied by Indonesian migrant workers to children who live in their hometowns. Themes of communication using LDR should be focused on education aspects emphasizing on motivation, achievement, frame of future life, and daily activities for schools.
\end{abstract}

Keywords: social media, migrant workers, children education.

Https://doi.org/10.30957/cendekia.v13i1.59.

\section{PENDAHULUAN}

Pekerja migran perempuan Indonesia, pada satu sisi telah membawa manfaat yang sangat besar bagi peningkatkan perekonomian keluarga, tetapi pada sisi yang lain, telah menurunkan tingkat perhatian orang tua terhadap anak baik, tingkat kasih sayang, perhatian secara psikologis, pendidikan, kesehatan, pendidikan norma, pendidikan agama, dan tata krama.

Saat ini, para migran lebih banyak menggunakan media sosial seperti whatsApp, Instagram $(I G)$, email, facebook $(F B)$, dan media sosial lainnya dalam berkomunikasi dengan anak dan anggota keluarga lainya yang berada di tempat tinggal asal. Para TKI dalam melakukan komunikasi tidak hanya melalui telepon percakapan, akan tetapi mereka telah menggunakan berbagai fisilitas yang ada di media sosial mereka seperti videocall.

Mereka tidak hanya melakukan komunikasi tentang kabar berita, kesehatan, atau diskusi yang lain, akan tetapi komunikasi antara TKI dan anak, tetapi mereka juga mengabarkan tentang aktivitas sehari-hari, pengalaman, berbagai kebahagiaan yang 
CENDEKIA, Vol. 13. No. 1 April 2019

p-ISSN: 1978-2098; e-ISSN: 2407-8557

Https://soloclcs.org; Email: cendekiaoslo@gmail.com

Center of Language and Cultural Studies, Surakarta, Indonesia

Basrowi. 2019. Pemenfaatan Media Sosial oleh Tenega Kerja Indonesia dalam Proses

Pendidikan Anak Menggunakan Metode Belajar Long Distance Relationship.

Cendekia (2019), 13(1): 1-18. Https//doi.org/10.30957/cendekia.v13i1.59.

dialami, bahkan kadang-kadang juga mengungkapkan keluh kesah tentang kejadian yang tidak dikehendaki.

Banyak juga pemanfaatan media sosial untuk berkomunikasi antara anak dan ibu atau ayah yang lebih mengarah pada komunikasi tentang tugas dari guru mata pelajaran yang harus dikerjakan di rumah (pekerjaan rumah), perkembangan pendidikan, pertumbuhan badan, perkembangan psikologis, dan berbagai hal yang berkaitan dengan keterampilan praktis.

Saat ini, banyak juga media sosial digunakan oleh para TKI dan anak-anaknya untuk kegiatan yang lebih bermanfaat, seperti upaya untuk meningkatkan perhatian orang tua kepada anak, meskipun hanya melalui layanan media sosial. Namun, hal itu sungguh sangat berarti dari pada tidak sama sekali, mengingat adanya keterbatasan hambatan jarak secara fisik. Meskipun banyak ahli mengatakan bahwa, "Hambatan jarak secara fisik tidak membatasi jarak secara sosial." Tentu saja teori itu tidak salah, akan tetapi berkaitan dengan proses pendidikan dan pembelajaran dari orang tua kepada anak, tentu akan menghadapi berbagai kendala bila hanya mengandalkan media sosial.

Ke depan diharapkan, seluruh TKI dapat memanfaatkan media sosial yang mereka miliki untuk kegiatan yang lebih positif, terutama dalam proses belajar mengajar dengan anak. Saat ini, mayoritas anak-anak para TKI yang sedang bekerja di luar negeri, sedang duduk di tingkat sekolah dasar, sekolah menengah pertama, sekolah menengah atas, dan sebagian kecil sudah menempuh pendidikan di perguruan tinggi.

Ketika anak-anak masih duduk di bangku sekolah dasar dan sekolah menengah pertama, maka kehadiran orang tua terutama ibu pada saat anak belajar di rumah sangat dibutuhkan. Bukan hanya masukan secara ilmiah, akan tetapi juga dorongan moril, motivasi dan semangat belajar anak dapat ditingkatkan. Terutama dorongan dan motivasi dari Ibu, merupakan pemompa semangat yang tidak bisa dilupakan dalam pendidikan. Oleh karena itu, telepon, videocall, atau hubungan langsung antara ibu dan anak pada saat anak belajar sangat dibutuhkan. Anak akan merasa diperhatikan dan diawasi, sementara ibu merasa bangga karena anak mempunyai semangat belajar yang tinggi. Tentu saja, dampak positif bagi ibu yang saat ini sedang bekerja di luar negeri menjadi meningkat, sebagai dampak selalu mengikuti proses pendidikan anak baik saat belajar di sekolah maupun pada saat belajar di rumah.

Ibu yang saat ini sedang bekerja di luar negeri, meskipun dalam kondisi terpaksa karena harus berpisah dengan anak-anak mereka dan berpisah dengan keluarga, menjadi sedikit terhibur manakala semangat belajar anak-anaknya di kampung halaman diketahui sangat tinggi. Motivasi bekerja mereka di luar negeri, dengan segala kesulitannya, menjadi meningkat, karena remitan yang mereka kirimkan tiap bulan tidak habis sia-sia, tetapi tertanam dalam bentuk investasi pendidikan bagi anak-anaknya.

Sebagaimana diketahui, bahwa anak adalah aset yang paling berharga. Pendidikan juga merupakan modal bagi anak untuk mempersiapkan masa depannya. Ketika pendidikan anak tinggi, maka seluruh perjuangan orang tua dengan bekerja banting tulang di negeri orang akan terbayarkan. Kelelahan orang tua akan seketika hilang manakala cita-cita anak dan orang tua berkaitan dengan pendidikan anak tercapai. 
CENDEKIA, Vol. 13. No. 1 April 2019

p-ISSN: 1978-2098; e-ISSN: 2407-8557

Https://soloclcs.org; Email: cendekiaoslo@gmail.com

Center of Language and Cultural Studies, Surakarta, Indonesia

Basrowi. 2019. Pemenfaatan Media Sosial oleh Tenega Kerja Indonesia dalam Proses

Pendidikan Anak Menggunakan Metode Belajar Long Distance Relationship.

Cendekia (2019), 13(1): 1-18. Https//doi.org/10.30957/cendekia.v13i1.59.

Banyak sekali anak-anak TKI yang sudah menempuh studi di perguruan tinggi. Banyak juga di antara mereka yang sudah mendampingi anaknya hingga program pascasarjana bahkan hingga tingkat strata doktor. Semua itu, tidak lain berkat bimbingan dari orang orang. Selain, dorongan motivasi dan doa dari orang tua.

Sayangnya, masih ada juga berbagai permasalahan di lapangan sebagaimana hasil prasurvei penelitian. Data di lapangan menunjukkan bahwa kondisi psikologis anak pada saat anak ditinggal pergi salah satu atau kedua orang tuannya, mereka merasa murung dan mudah marah, akan tetapi setelah jangka waktunya agak lama, kondisi psikologi anak menjadi semakin terbiasa, apalagi setelah mereka bergaul dengan teman sebayanya. Mereka menjadi tidak merasa kesepian, dan bisa kembali bahagia, apalagi kebutuhan akan uang makan, uang sekolah, uang jajan tercukupi. Akhirnya, mereka merasa bahagia meskipun ditinggal bekerja orang tuanya di luar negeri.

Setelah anak semakin tumbuh besar usia sekolah menengah pertama atau sekolah menengah atas, mereka baru merasakan bahwa sesungguhnya pada dirinya merasa ada yang kurang terhadap kasih sayang orang tuanya. Karena sudah merasa kurang kasih sayang, banyak anak pekerja migran yang pada saat menginjak usia dewasa, mereka meminta berbagai barang keperluan hidupnya seperti sepeda motor, telephone mobile, dan berbagai keperluan lain yang lebih bersifat konsumtif.

Dampak negatif lain pada anak selama ditinggal menjadi TKI, yaitu, rendahnya kesadaran terhadap budaya hidup sehat. Tabel 1 berikut menguatkan hal tersebut.

Tabel 1. Budaya hidup sehat

\begin{tabular}{lcc}
\hline \multicolumn{1}{c}{ Budaya hidup sehat } & Amount & $\mathbf{\%}$ \\
\hline Makan tidak teratur & 65 & 100 \\
\hline Tidur tidak teratur & 34 & 52.30 \\
\hline Tidak terbiasa cuci tangan & 36 & 55.38 \\
\hline $\begin{array}{l}\text { Tidak tentu mandi 2x per } \\
\text { hari }\end{array}$ & 60 & 92.30 \\
\hline $\begin{array}{l}\text { Tidak tentu Gosok gigi 2 } \\
\text { per hari }\end{array}$ & 34 & 52.30 \\
\hline \multicolumn{1}{c}{ Means } & 45.8 & 70.46 \\
\hline
\end{tabular}

Data di lapangan menunjukkan bahwa sebagian besar anak pekerja migran kurang memperhatikan budaya hidup sehat. Kebiasaan hidup yang kurang sehat yang dilakukan yaitu makan terkadang tidak teratur. Jarang sekali ditemukan ada anak-anak di pedesaan yang tidur siang, mereka lebih senang bermain saat sesudah pulang sekolah, mereka hanya tidur pada saat malam hari. Mereka juga jarang sekali gosok gigi sebanyak dua kali per hari, mayoritas di antara mereka hanya gosok giri satu kali yaitu pada saat pagi hari sementara itu, mereka mayoritas tidak gosok gigi pada saat malam hari. Kebiasan cuci tangan juga jarang sekali terjadi pada anak-anak pekerja migran. Kebiasaan mandi dua kali juga jarang dilakukan, mereka hanya mandi pada soren hari, dan pada pagi hari meskipun sekolah, banyak di antar mereka yang hanya gosok gigi, cuci muka, dan membasahi rambutkan agar tampak seolah-olah sudah mandi. 
CENDEKIA, Vol. 13. No. 1 April 2019

p-ISSN: 1978-2098; e-ISSN: 2407-8557

Https://soloclcs.org; Email: cendekiaoslo@gmail.com

Center of Language and Cultural Studies, Surakarta, Indonesia

Basrowi. 2019. Pemenfaatan Media Sosial oleh Tenega Kerja Indonesia dalam Proses

Pendidikan Anak Menggunakan Metode Belajar Long Distance Relationship.

Cendekia (2019), 13(1): 1-18. Https//doi.org/10.30957/cendekia.v13i1.59.

Permasalahan lain yang dialami anak-anak TKI yaitu rendahnya prestasi belajar mereka. Sebagian besar dari mereka diasuh dengan penuh toleransi oleh orang tua tunggal, nenek atau kakek, paman atau bibi, om atau tante. Tabel 2 menunjukkan rendahnya prestasi belajar mereka.

Tabel 2. Ranking anak-anak migran di sekolah

\begin{tabular}{ccc}
\hline Peringkat kelas & Amount & $\%$ \\
\hline$<5$ & 5 & 7.69 \\
\hline $5-10$ & 17 & 26.15 \\
\hline$>10$ & 43 & 66.15 \\
\hline Total & 65 & 100 \\
\hline
\end{tabular}

Data di lapangan menunjukkan bahwa mayoritas anak-anak pekerja migran tidak mempunyai rangking yang bagus (kurang dari lima). Mayoritas mereka mempunyai rangking di atas sepuluh. Posisi rangking mereka yang rendah dapat dipahami, karena lemahnya perhatian dari orang tua mereka. Perhatian hanya berasal dari ayah atau dari kakek/nenek yang mengasuh mereka. Mereka yang merawat, lebih banyak memperhatikan makan dan kesehatan anak dan kurang memperhatikan tugas-tugas sekolah atau belajar anak. Para pengasuh di rumah merasa sudah cukup memperhatikan, manakala mereka sudah memberi makan yang layak. Pendidikan sudah mereka serahkan sepenuhnya kepada sekolah. Akibatnya, posisi rangking anak-anak migran menjadi mayoritas rendah. Anak-anak migran yang saat ini mempunyai rangking baik, lebih banyak disebabkan oleh tingginya motivasi belajar anak, bukan disebabkan oleh tingginya perhatian orang tua.

Permasalahan lain yang dihadapi oleh para anak TKI adalah, banyak perilaku negatif yang diperankan oleh mereka. Berikut merupakan gambaran akan perilaku yang kurang terpuji tersebut. (Tabel 3).

Tabel 3. Perilaku negatif anak-anak pekerja migrant

\begin{tabular}{lcc}
\hline \multicolumn{1}{c}{ Perilaku anak } & Amount & $\%$ \\
\hline Merokok & 1 & 1.53 \\
\hline Penyalahgunaan obat terlarang & 0 & 0 \\
\hline Suka kebut-kebutan saat bersepeda motor & 3 & 4.61 \\
\hline Suka berkelahi & 2 & 3.07 \\
\hline Perilaku negatif lainnya & 1 & 1.53 \\
\hline Normal (tidak ada perilaku menyimpang & 58 & 89.23 \\
\hline Total & 65 & $\mathbf{1 0 0}$ \\
\hline
\end{tabular}

Sumber: data hasil penelitian

Data di lapangan menunjukkan bahwa mayoritas anak-anak migran yang masih kecil belum menunjukkan perilaku kenakalan yang berarti. Mereka tidak merokok, menyalahgunakan obat, atau perilaku negatif lainnya. Akan tetapi, setelah mereka memasuki usia sekolah menengah pertama atau sekolah menengah atas, ada di antara mereka yang merokok. Di lokasi penelitian belum ditemukan secara riil terjadinya penyalahgunaan obat atau perilaku nagatif lainnya. Belum ditemukan anak pekerja 
CENDEKIA, Vol. 13. No. 1 April 2019

p-ISSN: 1978-2098; e-ISSN: 2407-8557

Https://soloclcs.org; Email: cendekiaoslo@gmail.com

Center of Language and Cultural Studies, Surakarta, Indonesia

Basrowi. 2019. Pemenfaatan Media Sosial oleh Tenega Kerja Indonesia dalam Proses

Pendidikan Anak Menggunakan Metode Belajar Long Distance Relationship.

Cendekia (2019), 13(1): 1-18. Https//doi.org/10.30957/cendekia.v13i1.59.

migran yang ditangkap pihak berwajib karena kasus penyalahgunaan atau mengkonsumsi obat terlarang. Belum ada juga anak TKI yang melakukan tidakan criminal, atau terlibat kasus hukum seperti mencuri atau membegal. Memang ada anak pekerja migran yang suka kebut-kebutan pada saat naik sepeda motor, bahkan mereka tidak menggunakan perangkat keselamatan baik helm maupun jaket pelindung badan. Banyak di antara anak-anak migran yang sudah mengendarai sepeda motor meskipun usia mereka belum 16 tahun sebagaimana usia minimum persyaratan mengurus surat ijin mengemudi.

Melihat fenomena di atas, penelitian ini ingin mencari orisinalitasnya dengan melakukan penelitian tentang pemanfaatan media sosial oleh TKI dalam proses pendidikan anak melalui proses pembelajaran Komunikasi Jarak jauh (LDR). Tema di atas, sama sekali belum pernah diteliti oleh para peneliti terdahulu, karena mayoritas lebih banyak kepada peran remitan terhadap pendidikan anak, peran remiten dalam pembelian alat komunikasi, pola pengasuhan anak TKI, dan lainnya, yang belum menyentuh pada pemanfaatan media sosial dalam penanaman nilai-nilai adukasi kepada anak.

\section{LANDASAN TEORI}

McQuail (2006:26) dalam bukunya yang berkaitan dengan "Mass communication theory" menyimpulkan bahwa, "Ponsel merupakan media baru dalam perkembangan teknologi komunikasi. Teknologi yang digambarkan sebagai "media baru" bersifat digital, integratif, interaktif, dapat dimanipulasi, serta bersifat jaringan, padat, mampat, dan tidak memihak, yang bermanfaat dalam memudahkan seseorang untuk memperoleh suatu hal yang diinginkannya, sebagai media transaksi jual beli, sebagai media hiburan, sebagai media komunikasi yang efisien, dan sarana pendidikan."

Masih berkaitan dengan media komunikasi, Littlejohn (1999:337) menyatakan bahwa, "Karakteristik eksposur atau terpaan media dapat diukur melalui dimensidimensi: pertama, selectivity yaitu kemampuan audience dalam menetapkan pilihan terhadap media dan isi yang akan dieksposnya. Kedua, intentionally yaitu tingkat kesengajaan audience dalam menggunakan media atau kemampuan dalam mengungkapkan tujuan-tujuan penggunaan media. Ketiga, utilitarianism yaitu kemampuan audience untuk mendapatkan manfaat dari penggunaan media. Keempat, involvement yaitu keikutsertaan pikiran dan perasaan audience dalam menggunakan media dan pesan media yang diukur dari frekuensi maupun intensitas. Kelima, previous to influence, yaitu kemampuan untuk melawan arus pengaruh media."

Adapun Rosengren, et.al. dalam Cacace, et.al. (2014) membahas teori uses and gratification berasumsi bahwa, "Khalayak pada dasarnya bersifat aktif, selektif dan goal oriented dalam menggunakan media untuk memenuhi kebutuhan dan kepentingannya. Media massa berkompetisi dengan sumber-sumber lainnya (saluran komunikasi antar pribadi, kelompok, organisasi, dan sebagainya) dalam upaya memenuhi kebutuhan dan kepentingan khalayak."

Hasil penelitian Felita dkk. (2016) menyimpulkan bahwa, "Para remaja memahami informasi yang diberikan akan mendapatkan insight bahwa penggunaan 
CENDEKIA, Vol. 13. No. 1 April 2019

p-ISSN: 1978-2098; e-ISSN: 2407-8557

Https://soloclcs.org; Email: cendekiaoslo@gmail.com

Center of Language and Cultural Studies, Surakarta, Indonesia

Basrowi. 2019. Pemenfaatan Media Sosial oleh Tenega Kerja Indonesia dalam Proses

Pendidikan Anak Menggunakan Metode Belajar Long Distance Relationship.

Cendekia (2019), 13(1): 1-18. Https//doi.org/10.30957/cendekia.v13i1.59.

media sosial tidak menentukan konsep diri mereka. Mereka mengakses media sosial setiap hari ketika ada waktu-waktu kosong, bahkan para remaja ini seringkali membuka media sosial pada saat pelajaran berlangsung di kelas. Semua kegiatan yang dilakukan di media sosial ditujukan untuk memberikan kesan bahwa diri mereka sociable, lucu, cantik, tampan, keren, berbakat, punya banyak teman, dan eksis."

Hasil penelitian asil penelitian Efendi, Astuti, dan Rahayu (2017) menunjukkan bahwa, "Tingkat penggunaan media baru di kalangan anak usia 8-12 tahun di Kabupaten Sukoharjo dalam kategori sedang $(1,89)$ dan interaksi sosialnya, dalam kategori tinggi $(2,45)$. Asumsi yang menyatakan bahwa semakin tinggi penggunaan media baru maka semakin rendah interaksi sosial anak dapat diterima kebenarannya dengan koefisien korelasi sebesar 0,54 pada derajat kebebasan 0,05 atau tingkat kepercayaan 95\%."

Hasil penelitian Lesatari (2016) menyimpulkan, "TKI beraspirasi positif memberi pendidikan lebih baik, aspirasi jangka panjang yakni menyiapkan biaya pendidikan, aspirasi jangka pendek agar kegiatan pendidikan lancar, serta aspirasi realistik adanya harapan anak bergelar sarjana. Pasangan TKI, aspirasi positifnya agar anak berpendidikan tinggi, aspirasi jangka panjangnya menyiapkan kebutuhan sekolah, aspirasi jangka pendek yaitu mengawasi kegiatan sekolah dan aspirasi realistiknya agar anak tidak menjadi TKI. Anak TKI beraspirasi positif meningkatkan prestasi, aspirasi jangka panjangnya memiliki cita-cita yang tinggi, aspirasi jangka pendeknya menekuni kegiatan yang diikuti dan aspirasi realistiknya ingin mendapatkan jenis pekerjaan yang diidamkan." Apabila digambarkan dalam bentuk tabel tampak sebagai berikut.

Tabel 4. Aspirasi TKI, Pasangat TKI, dan Anak TKI

\begin{tabular}{|c|c|c|c|}
\hline Apirasi & TKI & Pasangan TKI & Anak TKI \\
\hline Jangka Pendek & $\begin{array}{l}\text { kegiatan } \\
\text { lancar }\end{array}$ & $\begin{array}{l}\text { mengawasi } \\
\text { sekolah }\end{array}$ & $\begin{array}{l}\text { menekuni kegiatan yang } \\
\text { diikuti }\end{array}$ \\
\hline $\begin{array}{l}\text { Jangka } \\
\text { Panjang }\end{array}$ & $\begin{array}{l}\text { Menyiapkan } \\
\text { pendidikan }\end{array}$ & $\begin{array}{l}\text { menyiapkan } \\
\text { sekolah }\end{array}$ & $\begin{array}{l}\text { memiliki cita-cita yang } \\
\text { tinggi }\end{array}$ \\
\hline Positif & $\begin{array}{l}\text { memberi } \\
\text { lebih baik }\end{array}$ & berpendidikan & meningkatkan prestasi \\
\hline Realistik & $\begin{array}{l}\text { harapan anak bergelar } \\
\text { sarjana }\end{array}$ & $\begin{array}{l}\text { Agar anak tidak menjadi } \\
\text { TKI }\end{array}$ & $\begin{array}{l}\text { ingin mendapatkan jenis } \\
\text { pekerjaan yang diidamkan }\end{array}$ \\
\hline
\end{tabular}

Sumber: Lesatari (2016) diolah dan dimodifikasi.

Berkaitan dengan pengasuhan anak, penelitian Lailiyah (2018) menyimpulkan bahwa, "Kendala yang muncul dalam pengasuhan anak ialah sosok ibu yang kesulitan dalam memerankan diri sebagai ayah dan proses penyesuaian diri dari pihak pengasuh maupun anak serta hal yang berdampak dalam pengasuhan yang dilaksanakan oleh pihak pengasuh. Anak yang diasuh oleh ibu kandungnya ketika ayah bekerja sebagai TKI lebih memilih mengasuh dengan otoritatif. Anak yang diasuh bibinya ketika ibu kandungnya bekerja sebagai TKI lebih memilih mengasuh dengan cara permisif indulgen. Anak yang diasuh oleh kerabat jauh ketika kedua orangtuanya 
CENDEKIA, Vol. 13. No. 1 April 2019

p-ISSN: 1978-2098; e-ISSN: 2407-8557

Https://soloclcs.org; Email: cendekiaoslo@gmail.com

Center of Language and Cultural Studies, Surakarta, Indonesia

Basrowi. 2019. Pemenfaatan Media Sosial oleh Tenega Kerja Indonesia dalam Proses

Pendidikan Anak Menggunakan Metode Belajar Long Distance Relationship.

Cendekia (2019), 13(1): 1-18. Https//doi.org/10.30957/cendekia.v13i1.59.

bekerja sebagai TKI memiliki kombinasi atas pengasuhan yang dilakukan yakni otoritatif oleh kerabatnya dan permisif indiferent oleh orangtua kandungnya."

Berkaitan dengan manfaat menjadi TKI, hasil penelitian Prihanto (2012) menyimpulkan bahwa, "Dengan menjadi TKI, telah terjadia perubahan nasib, status sosial ekonomi, taraf hidup meningkat secara signifikan." Bahkan menurut temuan Subri (2012), "Migrasi internasional dalam wujud TKI ke berbagai negara di asia, eropa, dan amerika telah memberikan pengaruh yang positif bagi perkembangan tingkat pendidikan anak."

Adapun latar belakang seseorang memilih bekerja sebagai TKI, menurut Kajian Subri (2012) menyimpulkan, "Seorang warga negara mempunyai tekat yang kuat menjadi pekerja migran karena didorong oleh keinginan untuk menyekolahkan anaknya." Hal ini senada dengan pendapat Bougas (2016) bahwa, "banyak tenaga kerja di sektor pertanian yang berkeinginan untuk menjadi pekerja migran ke negara lain agar ia dapat menyekolahkan anaknya ke tingkat yang lebih tinggi." Menurut Subri (2012), "Perbedaan upah yang sangat mencolok telah menyebabkan sesorang melakukan migrasi internasional. Dengan harapan pendapatan meningkat dan kemampuan untuk menyekolahkan anak meningkat."

Berkaitan dengan tujuan menjadi TKI, penelitian Primawati (2011) menemukan, "Migrasi internasional merupakan jalan keluar untuk memecahkan permasalahan ekonomi, ketenagakerjaan, dan pendidikan anak." Menurut Todaro (2009) "Arus migrasi internasional akan terus berlangsung sampai adanya keseimbangan penghasilan. Para migran internasional akan selalu membandingkan upah tenaga kerja antara negara yang satu dengan negara lainnya.”.

Penelitian tentang manfaat remitan telah dilakukan oleh banyak ahli antara lain Spitzer (2016) yang mengatakan bahwa, "Remitan yang dikirimkan ke kampung halamannya untuk memenuhi berbagai kebutuhan hidup anggota keluarta." Senada penelitian itu, Kustanto (2009) menemukan bahwa, "Pengiriman sumbangan remitan yang dilakukan responden dari total pendapatan untuk keluarga di kampung halaman."

Hasil kajian Elanvito (2011) menemukan pekerja migran yang mempunyai tanggungan keluaga seperti orang tua, anak, istri atau suami. Khusus kepada anak, diharapkan dapat digunakan untuk melanjutkan sekolahnya." Triyanti, Moko, \& Afriandi (2013) menyebutkan, "Seorang migran akan berangkat menjadi pekerja migran internasional berharap ekonomi dan pendidikan anak meningkat." Karena menurut Bougas (2016) remitan yang dikirimkan oleh pekerja migran secara teoritik akan mampu meningkatkan pendidikan anak. Primawati (2011) menyebutkan "Remitan dalam kehidupan masyarakat hendaknya tidak hanya berpihak pada pengumpulan materi saja tetapi lebih memperhatikan orientasi masa depan anak dan keluarga dalam bentuk investasi di bidang pendidikan anak, maupun investasi pada aset produktif." Berkaitan dengan seluruh landasan teori di atas, penelitian ini hendak menemukan orisinalitasnya pada tataran pemanfaatan media sosial oleh TKI terhadap anak-anak mereka yang masih usia sekolah yang tinggal di kampung halaman yang berada di bawah pengasuhan anggota keluarga lainnya. 
CENDEKIA, Vol. 13. No. 1 April 2019

p-ISSN: 1978-2098; e-ISSN: 2407-8557

Https://soloclcs.org; Email: cendekiaoslo@gmail.com

Center of Language and Cultural Studies, Surakarta, Indonesia

Basrowi. 2019. Pemenfaatan Media Sosial oleh Tenega Kerja Indonesia dalam Proses

Pendidikan Anak Menggunakan Metode Belajar Long Distance Relationship.

Cendekia (2019), 13(1): 1-18. Https//doi.org/10.30957/cendekia.v13i1.59.

\section{METODE}

Motode penelitian yang paling tepat untuk memecahkan sekaligus menjawab permasalahan penelitian ini adalah desktrip-kualitatif. Langkah penelitian yang dilakukan meliputi, pertama, menentukan daerah penelitian yaitu di Kabupaten Tulang Bawang, provinsi Lampung; mengurus ijin penelitian, menentukan populasi yaitu seluruh pekerja migran di Tulang Bawang, serta memilih informan penelitian yang benar-benar menjadi informan kunci dan informan pendukung tanpa menyebutkan jumlahnya, karena yang menjadi kunci perhatian adalah kejenuhan dan kecukupan data. Kedua, pengumpulan data skunder dari Dinas Tenaga Kerja. Langkah ketiga, melatih asisten lapangan dengan materi tujuan penelitian, pemahaman pedoman wawancara, praktik wawancara dengan responden, antropometri, dan screening activities. Langkah keempat, turun lapangan dengan melakukan wawancara kepada para pekerja migran yang sedang cuti di kampung halaman dan para mantan pekerja migran yang sudah tidak memperpanjang kontrak. Langkah kelima, yaitu mengelola data dengan melakukuan pengecekan, pengklasifikasian, dan analisis data, interpretasi, dan penarikan simpulan.

\section{HASIL DAN BAHASAN}

Penelitian ini mengidenfikasi peran media sosial dalam meningkatkan motivasi belajar anak dalam belajar dengan tujuan akhir yaitu meningkatnya prestasi belajar anak TKI, dan tingkat pendidikan anak. Data telah diperoleh dengan menggunakan metode pengamatan partisipatif. Informasi inti atas penelitian ini, pertama hendak diidentifikasi karakteristik keluarga lama bekerja TKI, kondisi ekonomi keluarga, dan tingkat pendidikan anak.

\subsection{Karakteristik Pekerja Migrant di Lokasi Penelitian}

Beberapa karakterisitik pekerja migran, tingkat sosial ekonomi, pendidikan anak, dan kesehatan anak adalah sebagai berikut.

Tabel 5. Durasi Kepergian Orangtua Bekerja di Luar Negeri

\begin{tabular}{cccc}
\hline \multirow{2}{*}{ Usia anak (Tahun) } & \multicolumn{3}{c}{ Pihak yang menjadi pekerja migran } \\
\cline { 2 - 5 } & Ayah & Ibu & Ayah dan Ibu \\
\hline $1-2$ & 2 & 4 & 3 \\
\hline $2,1-4$ & 3 & 19 & 7 \\
\hline $4,1-6$ & 5 & 9 & 5 \\
\hline$>6$ & 1 & 7 & 15 \\
\hline Total & 11 & 39 &
\end{tabular}

Data di lapangan menunjukkan bahwa tidak sedikit pekerja migran yang mempunyai anak antara $1-2$ tahun sudah ditinggal ke luar negeri untuk menjadi pekerja migran, baik salah satu orang tua maupun keduanya. Mayoritas pekerja migran berangkat ke luar negeri meninggalkan anaknya pada usia anak antara 2,1 sampai dengan 4 tahun.

Tabel 6. Lama bekerja di luar negeri 
CENDEKIA, Vol. 13. No. 1 April 2019

p-ISSN: 1978-2098; e-ISSN: 2407-8557

Https://soloclcs.org; Email: cendekiaoslo@gmail.com

Center of Language and Cultural Studies, Surakarta, Indonesia

Basrowi. 2019. Pemenfaatan Media Sosial oleh Tenega Kerja Indonesia dalam Proses

Pendidikan Anak Menggunakan Metode Belajar Long Distance Relationship.

Cendekia (2019), 13(1): 1-18. Https//doi.org/10.30957/cendekia.v13i1.59.

\begin{tabular}{|c|c|c|c|}
\hline negeri (Tahun) & Male & Female & \\
\hline$<3$ & 4 & 7 & 11 \\
\hline $3-6$ & 7 & 17 & 24 \\
\hline $6,1-9$ & 6 & 11 & 17 \\
\hline$>9$ & 5 & 8 & 13 \\
\hline Total & 22 & 43 & 65 \\
\hline
\end{tabular}

Sumber: data diolah

Data di lapangan menunjukkan bahwa lama kontrak minimal tiga tahun. Mayoritas para pekerja migran memperpanjang kontrak pertama selama tiga tahun menjadi enam tahun. Kontrak kerja selama tiga tahun dirasakan masih kurang, karena belum mampu menutup seluruh biaya pemberangkatan, dan belum mampu menabung untuk membeli berbagai aset produktif yang dapat digunakan untuk menjamin kehidupan yang akan datang. Jumlah pekerja migran yang bekerja di atas enam tahun juga jumlahnya hanya sedikit, karena mereka merasa jenuh dan biasanya tidak mendapat ijin dari keluarganya.

Tabel 7. Metode komunikasi yang digunakan

\begin{tabular}{ccc}
\hline Metode Komunikasi & $\begin{array}{c}\text { Jumlah } \\
\text { responden }\end{array}$ & Urutan ke \\
\hline Telpon & 45 & 2 \\
\hline SMS & 21 & 9 \\
\hline WhatsApp/Telp WA/Vcall WA & 56 & 1 \\
\hline Telegram & 29 & 8 \\
\hline Twitter & 24 & 4 \\
\hline Facebook & 31 & 3 \\
\hline Instragram & 34 & 77 \\
\hline Email & & 6 \\
\hline ChatOn & 27 & 10 \\
\hline Line & 28 &
\end{tabular}

Sumber: Hasil wawancara terstruktur

Berdasarkan data yang ada, motode yang paling sering digunakan adalah dengan menggunakan layanan WhatsApp termasuk di dalamnya telepon dengan menggunakan fasilitas yang ada di WhatsApp, maupun VideoCall yang ada di fasilitas WA, disusul telepon langsung, istagram, facebook, telegram, line, chat on, dan lainnya.

Tabel 8. Frekwensi komunikasi perhari

\begin{tabular}{ccc}
\hline $\begin{array}{c}\text { Frekwensi komunikasi } \\
\text { perminggu }\end{array}$ & Jumlah responden & $\mathbf{\%}$ \\
\hline $1-2$ & 6 & 9,23 \\
\hline $3-4$ & 9 & 13,85 \\
\hline $5-6$ & 23 & 35,38 \\
\hline Lebih dari 6 & 27 & 41,54 \\
\hline JUMLAH & 65 & 100 \\
\hline
\end{tabular}

Sumber: Hasil wawancara terstruktur 
CENDEKIA, Vol. 13. No. 1 April 2019

p-ISSN: 1978-2098; e-ISSN: 2407-8557

Https://soloclcs.org; Email: cendekiaoslo@gmail.com

Center of Language and Cultural Studies, Surakarta, Indonesia

Basrowi. 2019. Pemenfaatan Media Sosial oleh Tenega Kerja Indonesia dalam Proses

Pendidikan Anak Menggunakan Metode Belajar Long Distance Relationship.

Cendekia (2019), 13(1): 1-18. Https//doi.org/10.30957/cendekia.v13i1.59.

Berdasarkan tabel di atas tampak bahwa mayoritas komunikasi antara orang tua dan anak lebihd ari 6 kali per minggu, berarti frekwensi yang sering tersebut dapat digunakan oleh Ibu dalam membimbing anak-anak mereka dalam belajar atau mengerjakan pekerjaan tugas sekolah yang dibawa ke rumah. Apabila diilustrasikan dalam bentuk diagram tampak sebagai berikut.

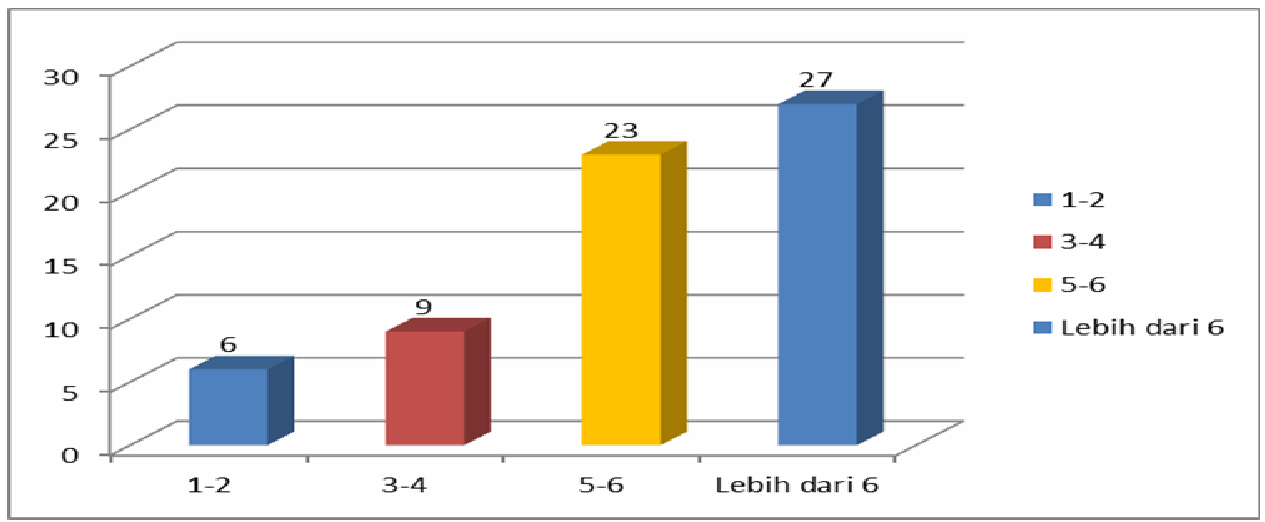

Diagram 1. Frekwensi komunikasi perhari

Frekwensi komunikasi perminggu antara TKI dan para keluarganya yaitu sebanyak lebih dari $6 \times$ ada 27 orang, yang dan paling rendah adalah antara 1-2 menit yaitu sebanyak 6 orang.

\subsection{Tema Komunikasi}

Tema komunikasi yang digunakan oleh TKI migran dengan anak dan frekuensinya disajikan parta tabel 9.

Tabel 9. Aspek yang dibicarakan

\begin{tabular}{ccc}
\hline Aspek yang dibicarakan & Jumlah responden & $\mathbf{\%}$ \\
\hline Kesehatan & 2 & 3,08 \\
\hline Kebutuhan rumah tangga & 7 & 10,77 \\
\hline Pedidikan & 44 & 67,69 \\
\hline Kondisi keluarga besar & 12 & 18,46 \\
\hline JUMLAH & 65 & 100
\end{tabular}

Sumber: Hasil wawancara terstruktur

Data di atas memberikan wawasan bahwa sebagian orang tua dalam melakukan komunikasi dengan anak, mayoritas membahas tentang pendidikan dilanjutkan dengan masalah rumah tingga, kesehatan, dan lainnya. 
CENDEKIA, Vol. 13. No. 1 April 2019

p-ISSN: 1978-2098; e-ISSN: 2407-8557

Https://soloclcs.org; Email: cendekiaoslo@gmail.com

Center of Language and Cultural Studies, Surakarta, Indonesia

Basrowi. 2019. Pemenfaatan Media Sosial oleh Tenega Kerja Indonesia dalam Proses

Pendidikan Anak Menggunakan Metode Belajar Long Distance Relationship.

Cendekia (2019), 13(1): 1-18. Https//doi.org/10.30957/cendekia.v13i1.59.

Tabel 10. Lama waktu melakukan komunikasi dalam setiap komunikasi

\begin{tabular}{ccc}
\hline $\begin{array}{c}\text { Lama komunikasi } \\
\text { (menit) }\end{array}$ & Jumlah responden & $\%$ \\
\hline $1-5$ & 10 & 15,38 \\
\hline $6-10$ & 12 & 18,46 \\
\hline $11-15$ & 20 & 30,77 \\
\hline $16-20$ & 15 & 23,08 \\
\hline Lebih dari 20 & 8 & 12,31 \\
\hline Rata-rata & 65 & 100
\end{tabular}

Sumber: Hasil wawancara terstruktur

Tabel di atas memberikan gambaran bahwa jumlah TKI yang melakukan komunikasi dengan anak dengan waktu antara 1-5 menit sebanyak 10 orang, antara 6-10 menit sebanyak 12 orang, antara 11-15 menit sebanyak 20 orang, antara 16-20 menit sebanyak 15 orang. Dengan demikian, rata-rata TKI dalam melakukan komunikasi dengan anak yaitu selama 11 menit.

Model komuniasi yang digunakan untuk sarana pendidikan yang terjadi antara TKI dan anak-anak mereka dapat digambarkan dalam diagram 2.

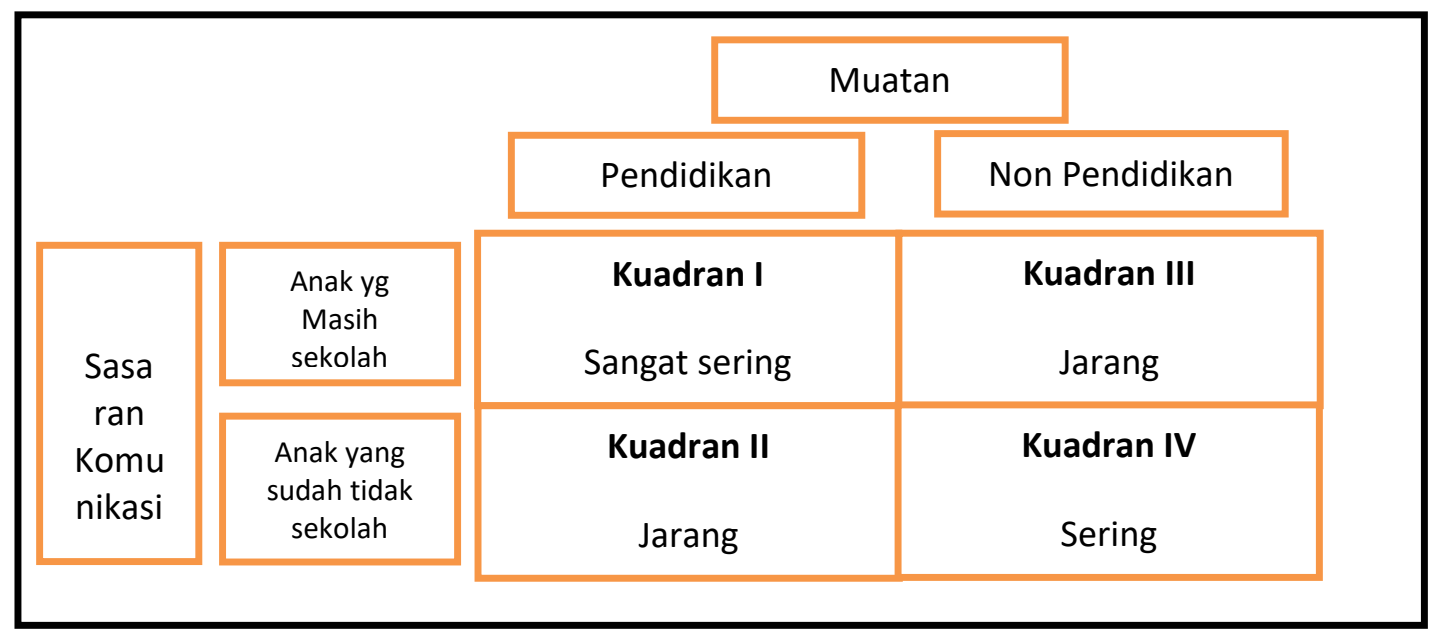

Diagram 2. Empat Kuadran Materi Pembicaraan Telepon dan Pihak yang dihubungi

Tabel empat kuadran di atas, memberikan gambaraan: Kuadran pertama, yaitu kegiatan yang paling sering dilakukan adalah menelpon kepada anak yang masih sekolah, masih memerlukan bimbingan, arahan dan kasih sayang dari seorang ibu, dengan muatan materi pendidikan yang ada kaitannya dengan sekolah.

Kuadran kedua, menelpon anak yang sudah tidak sekolah, dengan muatan pendidikan budi pekerti, tata krama, sopan santun, dan berbagai muatan pendidikan, agar anak-anak mempunyai tatakrama dan sopan santun meskipun tidak dididik oleh orang tuanya secar langsung secara tatap muka.

Kuadran ketiga, para TKI ketika menelpon anaknya nya yang masih sekolah maka jarang membicarakan hal-hal di luar urusan pendidikan, karena hal-hal di luar pendidikan telah ditanyakan kepada anak yang lain yang sudah tidak sekolah atau 
CENDEKIA, Vol. 13. No. 1 April 2019

p-ISSN: 1978-2098; e-ISSN: 2407-8557

Https://soloclcs.org; Email: cendekiaoslo@gmail.com

Center of Language and Cultural Studies, Surakarta, Indonesia

Basrowi. 2019. Pemenfaatan Media Sosial oleh Tenega Kerja Indonesia dalam Proses

Pendidikan Anak Menggunakan Metode Belajar Long Distance Relationship.

Cendekia (2019), 13(1): 1-18. Https//doi.org/10.30957/cendekia.v13i1.59.

bahkan sudah ditanyakan kepada anggota keluarga yang lain seperti suaminya maupun anggota keluarga terdekat lainnya.

Kuadran keempat, para TKI ketika penelpon anggota keluarga yang sudah tidak sekolah, lebih sering membicarakan hal lain yang tidak terkait dengan pendidikan anak. Seandinya menanyakan pendidikan, paling hanya sekedar rajin sekolah ataukah tidak, Sumbangan pendidikannya sudah dibayar atau belum, baju seragam sekolahnya masih layak pakai atau sudah waktunya diganti.

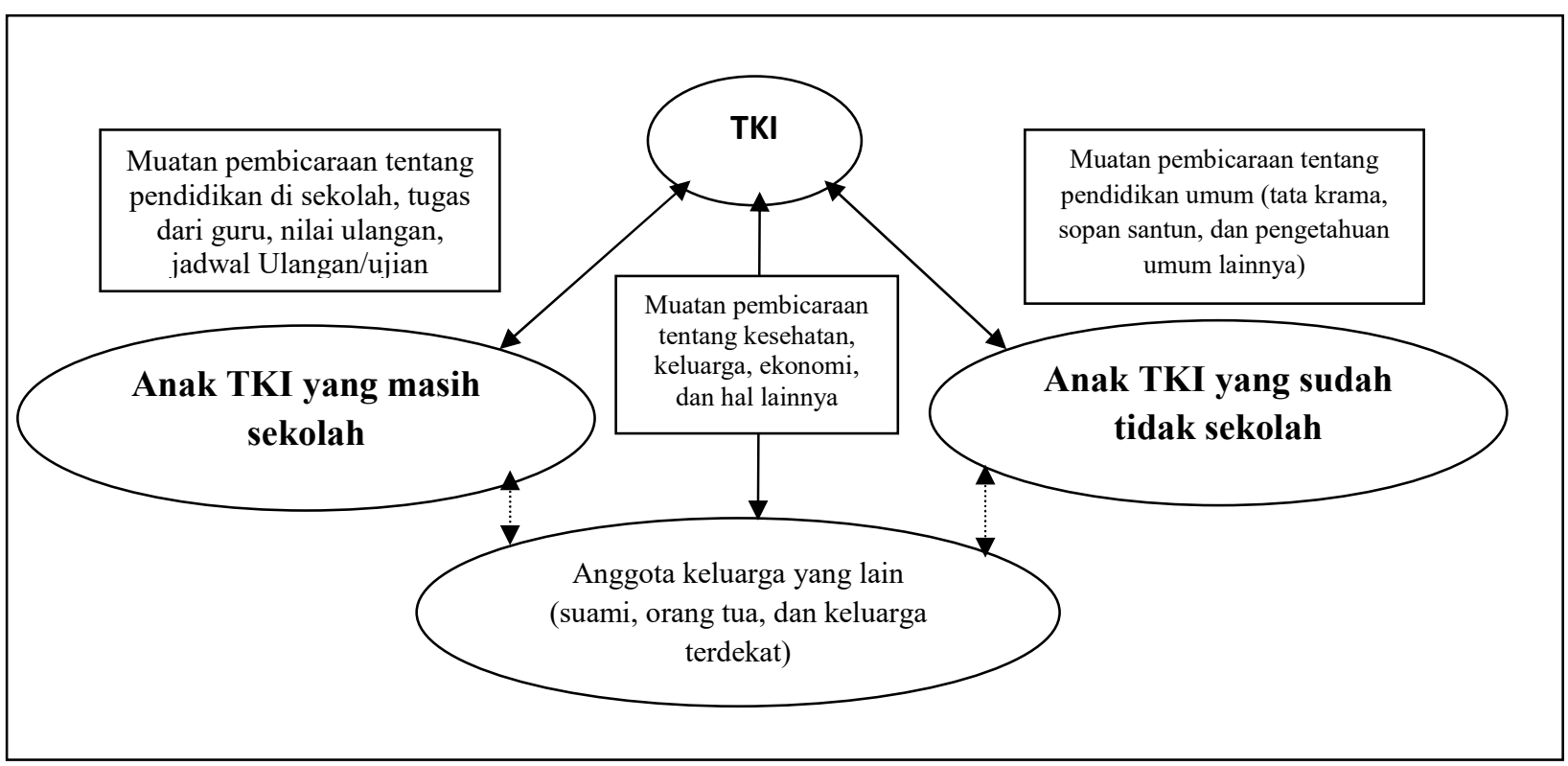

Diagram 3. Arah komunikasi dan muatan pesan komunikasi

Dengan demikian, ketika komunikasi antara TKI dan anak yang sedang sekolah, maka muatan Muatan pembicaraan tentang pendidikan di sekolah, tugas dari guru, nilai ulangan, jadwal Ulangan/ujian. Sedangkan, komunikasi antara TKI dan anak yang sudah tidak sekolah maka muatan komunikasinya itu pembicaraan tentang pendidikan umum (tata krama, sopan santun, dan pengetahuan umum lainnya). Sedangkan, muatan pembicaraan antara TKI dan Anggota keluarga yang lain (suami, orang tua, dan keluarga terdekat antara lain mengenai muatan pembicaraan tentang kesehatan, keluarga, ekonomi, dan hal lainnya.

Hasil penelitian ini menguatkan hasil penelitian Amalia, F.F. (2013) menyimpulkan bahwa, "Pemanfaatan handphone oleh TKI di Kampung Pandan-Dalam pada dasarnya adalah sebagai alat bantu untuk berkomunikasi dengan keluarga dan kerabat di Indonesia. Pemanfaatan internet mayoritas adalah TKI usia muda yang lebih terbuka terhadap perkembangan teknologi. Terdapat perubahan sosial budaya dari kedua pemanfaatan tersebut dilihat dari perubahan sikap serta pandangan TKI yang berubah seperti perubahan penggunaan alat bantu komunikasi, serta gaya hidup."

Berkaitan dengan Arah komunikasi dan muatan pesan komunikasi dapat digambarkan dalam diagram 4. 
CENDEKIA, Vol. 13. No. 1 April 2019

p-ISSN: 1978-2098; e-ISSN: 2407-8557

Https://soloclcs.org; Email: cendekiaoslo@gmail.com

Center of Language and Cultural Studies, Surakarta, Indonesia

Basrowi. 2019. Pemenfaatan Media Sosial oleh Tenega Kerja Indonesia dalam Proses

Pendidikan Anak Menggunakan Metode Belajar Long Distance Relationship.

Cendekia (2019), 13(1): 1-18. Https//doi.org/10.30957/cendekia.v13i1.59.

Dalam proses komunikasi dengan media sosial yang dimiliki, maka banyak sekali arah komunikas antara TKI dan anak yang masih dan sudah selesai sekolah, dan antara TKI dengan keluarga dekat mereka. Muatan komunikasi yang dibicarakan seluruhnya berbeda. Muatan pendidikan paling banyak adalah saat komunikasi dengan anaknya yang masih sekolah. Hanya saja mereka tidak mau melupakan muatan pendidikan meskipun bukan pendidikan budi pekerja, pendidikan nilai, pendidikan karakter, dan muatan pendidikan keterampilan lainnya. Adapun komunikasi dengan Anggota keluarga yang lain, tidak dibahas dalam penelitian ini.

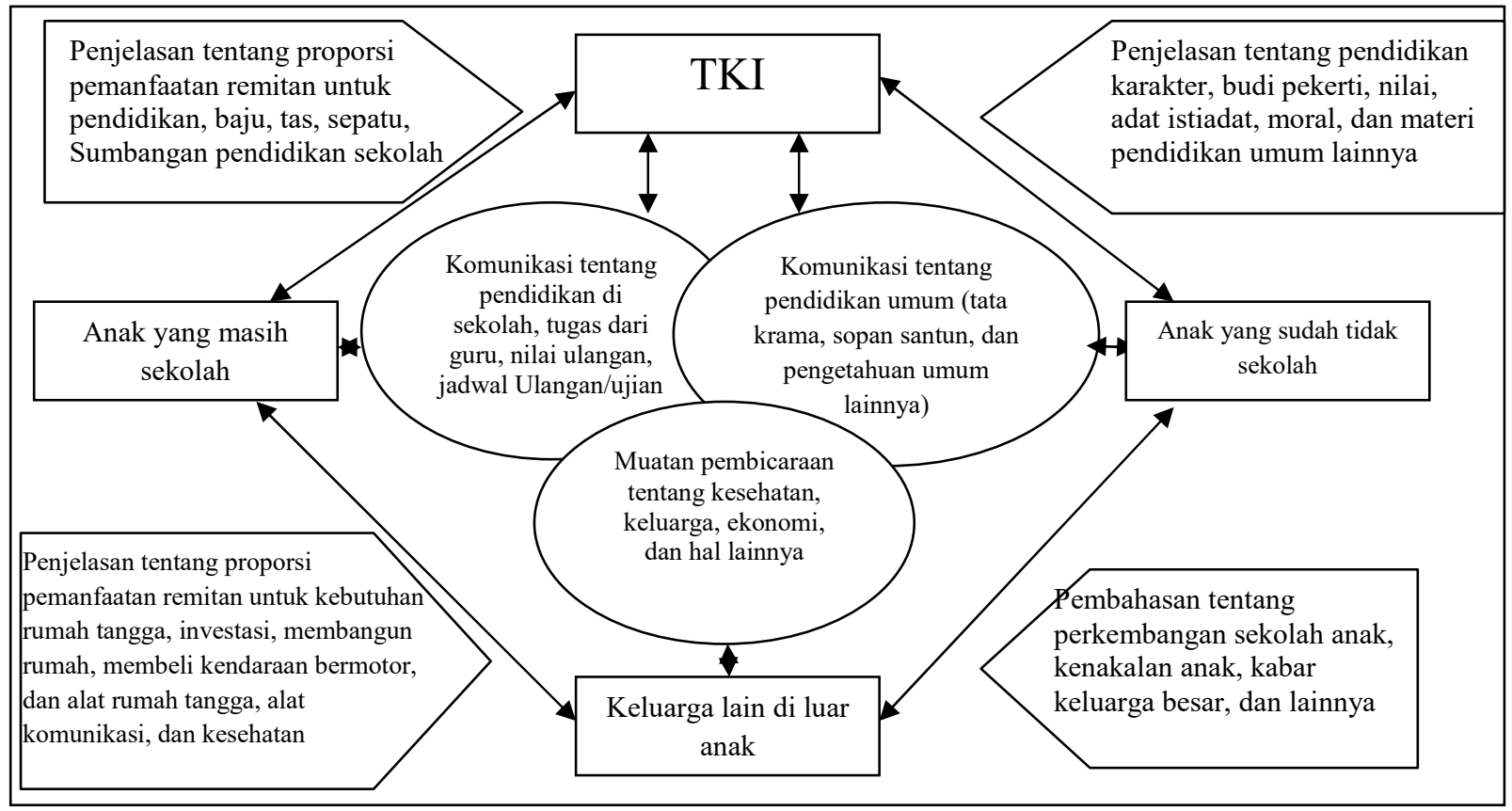

Diagram 4. Arah dan muatan pesan komunikasi.

Hasil penelitian ini pada dasarnya sesuai dengan temuan, Afriansyah (2016) yang menyimpulkan bahwa, "Pemenuhan hak kasih sayang anak dapat berjalan secara maksimal meskipun terjadi kekosongan peran ibu yang bekerja sebagai TKI, hal ini dikarenakan peran pengganti mampu menggantikan peran ibu secara baik. Sedangkan pemenuhan hak pendidikan anak tidak cukup hanya diserahkan kepada lembaga pendidikan namun keluarga mempunyai peran yang sangat penting dalam memberikan pendidikan bagi anak."

Berkaitan dengan bentuk dan arah komunikasi di atas apabila disederhanakan akan tampak sebagai berikut. 
CENDEKIA, Vol. 13. No. 1 April 2019

p-ISSN: 1978-2098; e-ISSN: 2407-8557

Https://soloclcs.org; Email: cendekiaoslo@gmail.com

Center of Language and Cultural Studies, Surakarta, Indonesia

Basrowi. 2019. Pemenfaatan Media Sosial oleh Tenega Kerja Indonesia dalam Proses

Pendidikan Anak Menggunakan Metode Belajar Long Distance Relationship.

Cendekia (2019), 13(1): 1-18. Https//doi.org/10.30957/cendekia.v13i1.59.

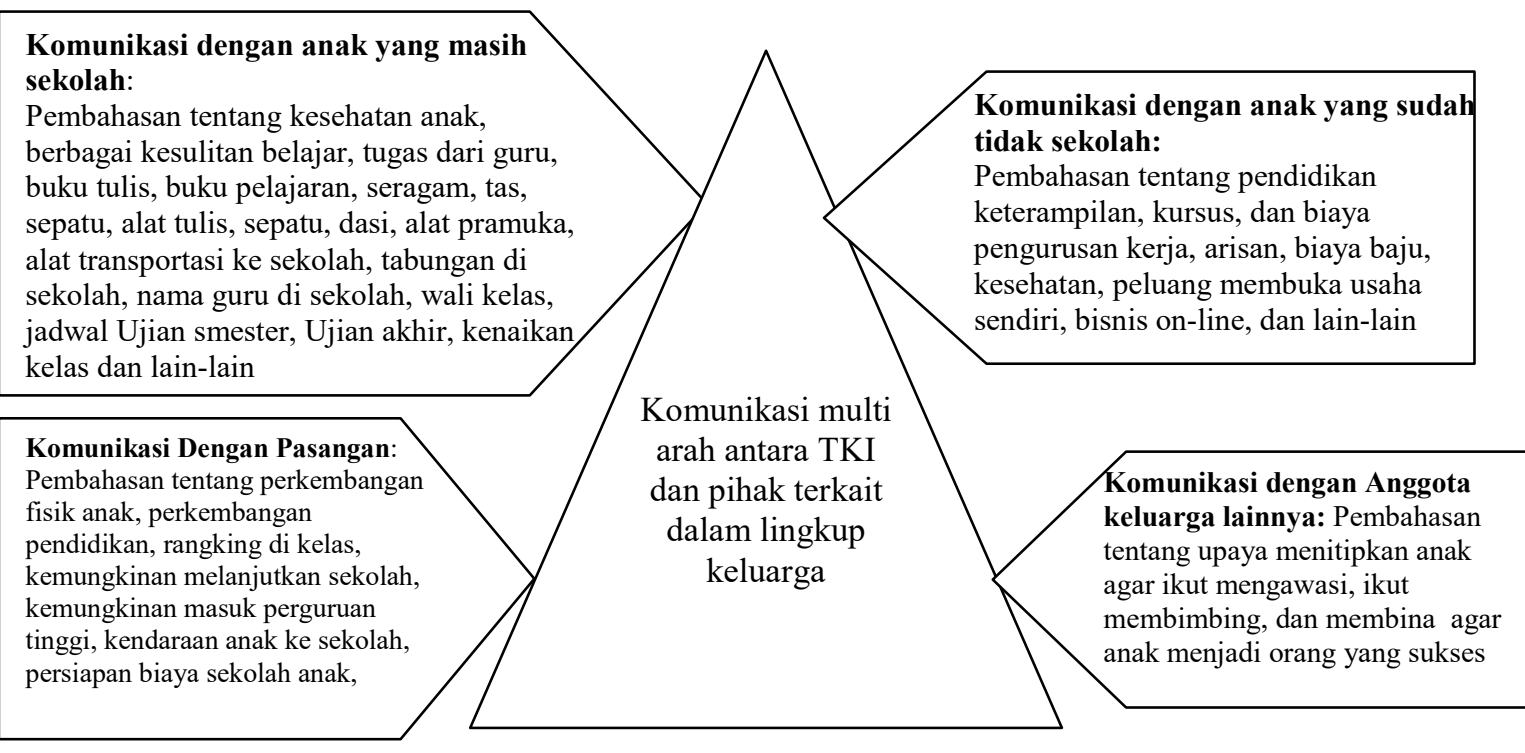

Antara TKI dan anggota keluarga jenis dan temanya sangat variatif, hanya saja masing-masing pembicaraan mempunyai tema masing-masing. Setiap pembicaraan antara TKI dengan anggota keluarga mempunyai tema yang berbeda-beda sesuai dengan posisi lawan bicaranya. Di sinilah letak, kapan seorang TKI dapat memotivasi, mengajarkan berbagai ilmu pengetahuan, memberikan cara belajar yang baik, dan jawaban atas pertanyaan yang berkaitan dengan tugas sekolah umpan materi pelajaran yang lainnya terutama kepad anaknya yang sedang sekolah.

Kondisi di atas sesuai dengan hasil penelitian Wulan dan Wahyuni (2015) yang menyimpulkan bahwa, "Peran ibu tidak dapat digantikan. Peran extended family kembali menguat dengan munculnya fenomena ibu bekerja. Pergantian peran antara ayah sebagai tulang punggung keluarga digantikan oleh ibu karena besarnya penghasilan sang istri mempengaruhi keseimbangan pengambilan keputusan dalam keluarga. Media sosial memberikan keuntungan dari segi kecepatan tanggapan atas masalah sehari-hari. Solusi dapat dengan mudah didiskusikan melalui kehadiran Black Berry Messener (BBM). Fitur seperti foto dan screen shot membantu percakapan antaranggota keluarga. Adapun kekurangan penggunaan media sosial dalam komunikasi keluarga terutama bagi keluarga yang menjalani kehidupan terpisah secara geografis adalah di sisi kesalahpahaman dalam memaknai situasi dari status dan foto-foto yang ditampilkan atau dikirimkan. Di sini tampak kekurangan terhadap pemahaman atas media literasi para TKW."

Hasil penelitian Ibni Yamin (2013) menyimpulkan bahwa "Pemanfaatan handphone sangat berpengaruh terhadap cara belajar siswa serta peningkatan prestasi siswa di sekolah. Dengan demikian, penggunaan handphone di lingkungan sekolah dapat dijadikan sebagai salah satu sumber belajar. Namun perlu adanya pengawasan dan 
CENDEKIA, Vol. 13. No. 1 April 2019

p-ISSN: 1978-2098; e-ISSN: 2407-8557

Https://soloclcs.org; Email: cendekiaoslo@gmail.com

Center of Language and Cultural Studies, Surakarta, Indonesia

Basrowi. 2019. Pemenfaatan Media Sosial oleh Tenega Kerja Indonesia dalam Proses

Pendidikan Anak Menggunakan Metode Belajar Long Distance Relationship.

Cendekia (2019), 13(1): 1-18. Https//doi.org/10.30957/cendekia.v13i1.59.

bimbingan dari pihak sekolah serta orang tua siswa agar tidak ada penyalahgunaan media handphone ke hal-hal yang bisa membawa dampak negatif bagi prestasi siswa di sekolah. Dengan adanya sumber belajar yang semakin berkembang pesat saat ini diharapkan mampu dimanfaatkan dengan baik untuk meningkatkan hasil belajar siswa di sekolah."

\section{SIMPULAN}

Temuan yang diperoleh melalui penelitian ini adalah:

1. Pemanfaatan media sosial yang dimiliki oleh para TKI dan anak-anak TKI dapat dimanfaatkan untuk hal-hal yang lebih positif, bukan hanya sebagai alat komunikasi, tetapi dapat dimanfaatkan untuk proses pembelajaran melalui komunikasi jarak jauh (LDR)

2. Media sosial yang paling sering digunakan untuk melakukan komunikasi antara TKI dan anak-anak TKI yang berada di kampung halaman adalah WA dan ditur lain yang ada di dalam WA seperti call-phone dengan WA dan $V$-call dengan WA, diikuti instagram, SMS, telpon, dan facebook.

3. Jumlah frekwensi menelpon antara 4-6 dalam satu minggunya, lama berkomunikasi berkisar antara 10-15 menit dalam setiap harinya. Materi yang dibicarakan meliputi pendidikan, kesehatan, kabar kesehatan keluarga, dan masalah keluarga.

4. Hasil penelitian berupa model pembelajaran dengan menggunakan Metode LDR yang bisa diterapkan oleh TKI kepada anak-anak yang tinggal di kampung halaman.

\section{Ucapan Terima Kasih}

Terima kasih disampaikan kepada pihak Sekolah Tinggi Ekonomi dan Bisnis Islam (STEBI) Lampung yang telah berkenan mendukung seluruh aspeknya mulai dari perijinan, pembiayaan, dan seluruh biaya seminar dan publikasinya, sehingga naskah jurnal ini dapat terpublikasikan dan dapat dibaca oleh semua pihak, sebagai sumber referensi ilmiah, yang tidak hanya akan memberi sumbangan teoritik, tetai juga diharapkan mampu memberikan sumbangan bagi perumusan kebijakan di bidang pekerja migrant.

\section{DAFTAR PUSTAKA}

Afriansyah, H. 2016. "Pemenuhan Hak Anak oleh Keluarga TKI (Studi di Desa Keboireng, Besuki, Kabupaten Tulungagung)," Tesis, Malang: UIN Maulana Malik Ibrahim, online: http://etheses.uin-malang.ac.id/11296/1/13780002.pdf accessed Feb. 18, 2019

Amalia, F.F. 2013. "Pemanfaatan Teknologi Informasi dan Komunikasi Oleh Tenaga Kerja Indonesia Serta Pengaruhnya Terhadap Perubahan Sosial Budaya Di Kampung Pandan Dalam, Ampang Jaya, Malaysia.” Jurnal Bumi Indonesia, 2(1). Online: http://lib.geo.ugm.ac.id/ojs/index.php/jbi/article/view/144/141 accessed Feb. 18, 2019 
CENDEKIA, Vol. 13. No. 1 April 2019

p-ISSN: 1978-2098; e-ISSN: 2407-8557

Https://soloclcs.org; Email: cendekiaoslo@gmail.com

Center of Language and Cultural Studies, Surakarta, Indonesia

Basrowi. 2019. Pemenfaatan Media Sosial oleh Tenega Kerja Indonesia dalam Proses

Pendidikan Anak Menggunakan Metode Belajar Long Distance Relationship.

Cendekia (2019), 13(1): 1-18. Https//doi.org/10.30957/cendekia.v13i1.59.

Bougas, M. P. 2016. “Analisis alokasi penggunaan remitan untuk pendidikan anak (studi kasus 10 kecamatan di Kabupaten Malang)." Skripsi (naskah publikasi).

Malang: FEB Universitas Brawijaya. Online:

http://download.portalgaruda.org/article.php?\% Accessed Oct. 11, 2017

Cacace, A. T., et.al. 2014. "Scientific Foundations of Audiology: Perspectives from Physics, Biology.” https://books.google.co.id/books?id=EtAyDAAAQBAJ Accessed Feb. 16, 2019

Elanvito. 2010. "Remitan dan dampaknya di tingkat rumah tangga, komunitas dan makro. Kajian literatur." Online:

download.portalgaruda.org/article.php?...Analisis\%20Alokasi\%20Penggunaan\%20R emit. Accessed Feb. 16, 2019

Efendi, Astuti, dan Rahayu. 2017. "Analisis Pengaruh Penggunaan Media Baru Terhadap Pola Interaksi Sosial Anak Di Kabupaten Sukoharjo.” Jurnal Penelitian Humaniora, $18(2), 12-24$. journals.ums.ac.id/index.php/humaniora/article/download/5188/3455 Accessed Feb. 16, 2019

Freedman, R. 1983. Teori-teori penurunan fertilitas: suatu tinjauan. Yogyakarta: Pusat Penelitian dan Studi Kependudukan Universitas Gadjah Mada.

Felita, P., dkk. 2016. "Pemakaian Media Sosial Dan Self Concept Pada Remaja." Jurnal Ilmiah Psikologi MANASA. 5(1), 30-41. Available Online: ojs.atmajaya.ac.id/index.php/manasa/article/view/585/456 Accessed Feb. 11, 2019

Hanson, Ralph E. "Mass Communication: Living in a Media World." https://books.google.co.id/books?id Accessed Feb. 17, 2019

Kustanto, 2009. "Mobilitas tenaga kerja ke malaysia serta sumbangan remitan terhadap ekonomi keluarga di Kabupaten Tulungagung Propinsi Jawa Timur." Skripsi. Solo: Fakultas Geografi UMS diunduh dari http://eprints.ums.ac.id/6517/1/E100050058.pdf accessed Nov. 15, 2015

Lailiyah, F. 2018. "Problematika Pengasuhan Anak Pada Keluarga TKI (Studi di Desa Golokan Kecamatan Sidayu Kabupaten Gresik)." Skripsi. Surabaya: FISIPOL Unair. http://journal.unair.ac.id/download-fullpapers-kmnts8d34345aa3full.pdf Accessed Oct. 11, 2017

Lestari, Tri. 2016. "Aspirasi Pendidikan Dalam Keluarga Tenaga Kerja Indonesia (TKI) Di Desa Jangkaran Kecamatan Temon Kabupaten Kulon Progo.” Jurnal Kebijakan Pendidikan, 5(1). Available online: journal.student.uny.ac.id/ojs/index.php/sakp/article/view/1422 Accessed Feb. 17, 2019 
CENDEKIA, Vol. 13. No. 1 April 2019

p-ISSN: 1978-2098; e-ISSN: 2407-8557

Https://soloclcs.org; Email: cendekiaoslo@gmail.com

Center of Language and Cultural Studies, Surakarta, Indonesia

Basrowi. 2019. Pemenfaatan Media Sosial oleh Tenega Kerja Indonesia dalam Proses

Pendidikan Anak Menggunakan Metode Belajar Long Distance Relationship.

Cendekia (2019), 13(1): 1-18. Https//doi.org/10.30957/cendekia.v13i1.59.

Littlejohn, S.W. "Theories of human communication." https://openlibrary.org/books/OL348712M/Theories_of human_communication dan https://trove.nla.gov.au/work/8318444 Accessed Feb. 17, 2019

Marisol Sandoval. "From Corporate to Social Media: Critical Perspectives on Corporate." https://www.worldcat.org/title/mcquails-mass-communicationtheory/oclc/444174608? referer=\&ht=edition Accessed Feb. 15, 2019

McQuail. Denis, "McQuail's mass communication theory." https://www.worldcat.org/title/mcquails-mass-communicationtheory/oclc/444174608? referer=\&ht=edition Accessed Feb. 14, 2019

Primawati, A. 2011. "Remitan Sebagai Dampak Migrasi Pekerja Ke Malaysia." Sosiokonsepsia, 16(2). Available Online: http://puslit.kemsos.go.id/download/144 Accessed Oct. 11, 2017

Hanson, Ralph E. 2019. "Mass Communication: Living in a Media World." https://books.google.co.id/books?id=ZX5ZDwAAQBAJ\&pg= Accessed Feb. 17, 2019

Sandoval, Marisol. "From Corporate to Social Media: Critical Perspekctive on Corporate.” Online: journals.sagepub.com/doi/abs/10.../0267323115627078a Accessed Feb. 17, 2019

Spitzer, Denise L. 2016. "Return Migrant Entrepreneurship and the Migration and Development Agenda: A Focus on Filipino and Indonesian Migrant Workers." Migration, Mobility, \& Displacement 2 (2): 24-39. Online: https://journals.uvic.ca/index.php/mmd/article/view/15311 Accessed Oct. 11, 2017

Subri, M. 2012. Ekonomi sumber daya manusia dalam prespektif pembangunan. Jakarta:PT. Raja Grafindo Persada.

Todaro, M.P \& Stephen, S.C. 2006. Pembangunan ekonomi, edisi 09. Jilid 1. Jakarta: Erlangga.

Triyanti, D., Moko, F.E., \& Afriandi, T. 2013. "Remitansi: determinan dan dampak terhadap pembangunan daerah asal." Jakarta: Program Pascasarjana Kajian Studi Kependudukan dan Ketenagakerjaan Universitas Indonesia. Online: https://www.worldcat.org/title/mcquails-mass-communicationtheory/oclc/444174608? referer $=\&$ ht $=$ edition Accessed Oct. 12, 2017 
CENDEKIA, Vol. 13. No. 1 April 2019

p-ISSN: 1978-2098; e-ISSN: 2407-8557

Https://soloclcs.org; Email: cendekiaoslo@gmail.com

Center of Language and Cultural Studies, Surakarta, Indonesia

Basrowi. 2019. Pemenfaatan Media Sosial oleh Tenega Kerja Indonesia dalam Proses

Pendidikan Anak Menggunakan Metode Belajar Long Distance Relationship.

Cendekia (2019), 13(1): 1-18. Https//doi.org/10.30957/cendekia.v13i1.59.

Wulan, R.R. dan Wahyuni, I.I. 2015. "Komunikasi Keluarga Lintas Negara: Studi

Kasus Tentang Penggunaan Media Sosial Sebagai Sarana Komunikasi Keluarga

Tenaga Kerja Wanita Indonesia." Jurnal Penelitian Komunikasi Dan

Pembangunan. 16(2), 76-87. Online:

https://media.neliti.com/media/publications/231002-komunikasi-keluarga-lintasnegara-studi-11bd0b97.pdf accessed Feb. 18, 2019.

Yamin, Ibni. 2013. "Pemanfaatan Handphone Sebagai Sumber Belajar Siswa SMP Negeri Arun Lhokseumawe." Syah Kuala: FKIP Unsyah. Online: http://etd.unsyiah.ac.id/index.php? $\mathrm{p}=$ show detail\&id=9421 Accessed Feb. 18, 2019 